\title{
Germinação e tolerância à dessecação de sementes de bacaba (Oenocarpus bacaba Mart.) ${ }^{1}$
}

\author{
Anderson Cleiton José2*, Eduardo Andrea Lemus Erasmo ${ }^{3}$, Adriano Barros Coutinho ${ }^{3}$
}

RESUMO - A Bacaba (Oenocarpus bacaba) é uma palmeira típica da região amazônica, muito utilizada para alimentação pela população local, na região norte do Brasil. Objetivou-se com esta pesquisa avaliar o efeito de diferentes temperaturas e substratos na germinação das sementes de bacaba e fazer a classificação fisiológica das sementes quanto à secagem e ao armazenamento. Os frutos foram coletados em Caseara, Tocantins, Brasil. A germinação foi realizada em diferentes temperaturas e substratos após o beneficiamento. A viabilidade também foi avaliada após a secagem a diferentes conteúdos de água para classificação fisiológica quanto à secagem e ao armazenamento. O melhor substrato para a germinação de sementes de bacaba foi sobre areia. Não foi verificado efeito da temperatura na germinação das sementes, exceto quando as sementes foram incubadas a $35{ }^{\circ} \mathrm{C}$, temperatura que não foi observada germinação. Apesar de não haver efeito da maioria das temperaturas testadas sobre a porcentagem final de germinação, quando as sementes foram incubadas nas temperaturas de $30^{\circ} \mathrm{C}$ e $25-35^{\circ} \mathrm{C}$ observou-se maior velocidade de germinação. As sementes de bacaba não toleram a secagem abaixo de $0,36 \mathrm{~g} \mathrm{H}_{2} \mathrm{O} \mathrm{g}^{-1}$ peso seco, sendo portanto classificadas como recalcitrantes.

Termos para indexação: viabilidade, espécie florestal, recalcitrante, secagem.

\section{Germination and storage behaviour of bacaba (Oenocarpus bacaba Mart.) seeds}

\begin{abstract}
Bacaba (Oenocarpus bacaba) is a palm species typical from Amazon region, widely used by local people for feeding. This work aimed to evaluate the effect of different conditions of temperature and substrate in the germination of seeds and to determine the seed storage behaviour of bacaba (Oenocarpus bacaba) seeds. Fruits were collected at Caseara, Tocantins, Brazil. The germination was carried out at different temperatures and substrates after cleaning. Seed viability was also determined after drying at different water content in order to determine the seed storage behavior. The best substrate for germination of bacaba seeds was in sand. It was not verified effect of temperature on the germination of the seeds, except when seeds were incubated at $35^{\circ} \mathrm{C}$, which germination was not observed. Although there is no effect on the most of the temperature tested on the final percentage of germination, seeds incubated at $30{ }^{\circ} \mathrm{C}$ and $25-35{ }^{\circ} \mathrm{C}$ showed higher speed of germination. Seeds of bacaba cannot be dried below $0,36 \mathrm{~g} \mathrm{H}_{2} \mathrm{O} \mathrm{g}^{-1}$ dry weight, and so they are classified as recalcitrant.
\end{abstract}

Index terms: forest species, drying, recalcitrant, viability.

\section{Introdução}

A família Arecaceae é constituída por mais de 2.500

${ }^{1}$ Submetido em 05/09/2011. Aceito para publicação em 12/04/2012.

${ }^{2}$ Departamento de Ciências Florestais, UFLA, Caixa Postal 3037, 372000-000-Lavras, MG, Brasil. espécies, distribuídas em 200 gêneros, predominantemente nos trópicos. Constitui a terceira família botânica economicamente mais importante, depois das famílias

${ }^{3}$ Departamento de Agronomia, UFT, Caixa Postal 66, 77402-970-Gurupi, TO, Brasil.

*Autor para correspondência <acjose@dcf.ufla.br> 
Poaceae e Fabaceae (Janick e Paull, 2006). O Brasil é considerado o terceiro país com maior diversidade de palmeiras nativas, possuindo aproximadamente 37 gêneros e 387 espécies. Desse total, 32 gêneros e 232 espécies estão na região amazônica, sendo a maioria dessas espécies considerada de importância econômica, social e ambiental (Zeven, 1964; Valois, 2009).

As palmeiras, especialmente na região amazônica, têm sido utilizadas pelo homem como fonte energética na dieta alimentar, como material para construção de casas (estruturas e cobertura), utensílios caseiros, como bebida, ou fazendo parte da arborização regional (Kahn e Castro, 1985; Mendonça e Araujo, 1999; Viégas e Müller, 2000) e fabricação de artesanato, incluindo as biojóias.

Atualmente, devido às mudanças climáticas globais, tem-se buscado alternativas que reduzam as emissões de gases causadores do efeito estufa. Nesse sentido, as ações internacionais estão voltadas para o desenvolvimento de programas de substituição dos combustíveis fósseis por combustíveis produzidos a partir de fontes renováveis, como o biodiesel. No Brasil existem várias iniciativas privadas e públicas que visam à produção de energia por fontes sustentáveis. Dentre essas, destaca-se o Plano Nacional de Agroenergia, lançado em 2006, e o Programa Nacional de Produção e Uso do Biodiesel (PNPB).

Dessa forma, é primordial a realização de estudos que forneçam informações que auxiliem na domesticação de espécies nativas com potencial para exploração econômica. A utilização dessas espécies tem como objetivo priorizar arranjos produtivos locais, tais como sistemas agroflorestais e o manejo extrativista sustentável, de forma que os mesmos não desloquem os cultivos alimentares e nem avancem sobre áreas de florestas (Costa e Marchi, 2008). Neste contexto, as palmeiras nativas apresentam-se como uma alternativa para composição dos plantios.

Dentre as palmeiras com importância econômica, a bacaba, espécie nativa da região norte do Brasil, é bastante explorada pela população local no preparo de suco, vinho, sorvete, palmito e extração de óleo comestível (Lorenzi, 1996). Entretanto, pouco se conhece sobre as características silviculturais e potencial de exploração desta espécie. A utilização racional de qualquer espécie exige o conhecimento de vários aspectos relacionados à fisiologia das sementes, tais como germinação e a tolerância à dessecação, o que facilitará o armazenamento e a produção de mudas para atender aos programas de plantio.

Uma das formas de determinar a qualidade das sementes é através da realização de teste de germinação, o qual é realizado sob condições de temperatura e substrato ideais para cada espécie (Brasil, 2009).

As sementes de diferentes espécies apresentam comportamentos variáveis em relação à temperatura, o que pode fornecer informações de interesse biológico e ecológico (Labouriau, 1983). Dentro da faixa de temperatura em que as sementes de uma espécie germinam, há uma temperatura ótima, denominada como aquela em que ocorre o máximo de germinação em menor intervalo de tempo. Temperaturas mínimas e máximas são consideradas como sendo os limites, que uma vez superados, a germinação é nula. Algumas espécies, principalmente aquelas não domesticadas apresentam melhor comportamento germinativo quando submetidas à alternância de temperatura (Salomão et al., 1995; Albuquerque et al., 1998; MarcosFilho, 2005). Essa alternância de temperatura corresponde às flutuações naturais encontradas em condições naturais, especialmente clareiras. Por outro lado, existem espécies que a germinação de suas sementes é favorecida quando submetidas à temperatura constante (Lima et al., 1997).

O substrato utilizado nos testes de germinação também apresenta grande influência na germinação, pois fatores como aeração, estrutura, capacidade de retenção de água, grau de infestação de patógenos, entre outros, podem variar de um substrato para outro, favorecendo ou prejudicando a germinação das sementes (Gosling, 2002). Na escolha do material para substrato, deve ser levado em consideração o tamanho da semente, sua exigência com relação à umidade, sensibilidade ou não à luz, a facilidade que este oferece para o desenvolvimento e a avaliação das plântulas (Brasil, 2009).

Outro ponto importante que deve ser observado, para que uma espécie seja utilizada em programas de reflorestamento, ou quando se pretende fazer a conservação ex situ em bancos de sementes é o conhecimento prévio do seu comportamento fisiológico durante a secagem e armazenamento, já que nem todas as sementes são tolerantes à dessecação, exigindo condições especiais de armazenamento (Hong et al., 1996).

Atualmente as sementes são classificadas em três categorias quanto ao seu comportamento durante a dessecação e armazenamento sendo as sementes ortodoxas, aquelas que toleram dessecação a baixos conteúdos de água ( $2 \%$ a $5 \%$, em base úmida) e podem ser armazenadas em baixas temperaturas $\left(-20^{\circ} \mathrm{C}\right)$, condições que maximizam o tempo de armazenamento; sementes intermediárias, que não toleram a dessecação a baixos conteúdos de água $(10 \%-12 \%)$, mas que podem ser armazenadas a baixas temperaturas (geralmente acima de $0{ }^{\circ} \mathrm{C}$ ); e sementes 
recalcitrantes, comuns entre as espécies florestais da região tropical, as quais não toleram dessecação a baixos conteúdos de água ( $<12 \%$, em base úmida), e nem o armazenamento a baixas temperaturas (Roberts, 1973; Ellis et al., 1990; Hong et al., 1996; Sacandé et al., 2004).

No entanto, os estudos relacionados às sementes de bacaba ainda são incipientes e exploratórios (Mendonça e Araújo, 1999), e segundo Lorenzi (1996) a germinação das sementes desta espécie é lenta e desuniforme e sua longevidade no armazenamento é baixa. Assim, face ao exposto, objetivou-se com esse trabalho, avaliar o efeito de diferentes condições de temperaturas e substratos na germinação das sementes de bacaba, e avaliar a tolerância à dessecação e ao armazenamento.

\section{Material e Métodos}

Os experimentos foram conduzidos no Laboratório de Análises de Sementes da Universidade Federal do Tocantins, Campus Universitário de Gurupi - TO e no Laboratório de Sementes Florestais da Universidade Federal de Lavras - MG.

Os frutos de Oenocarpus bacaba foram coletados de árvores no município de Gurupi, Tocantins, em dezembro de 2010. Após a coleta, foram mantidos em sacos plásticos por três dias para que ocorresse a fermentação dos frutos. Posteriormente, o epicarpo e o mesocarpo dos frutos foram removidos por meio do atrito manual contra uma peneira (maceração) sob água corrente e secados à sombra para remoção da água superficial. As sementes foram armazenadas em saco plástico e acondicionadas a temperatura de $20^{\circ} \mathrm{C}$ durante 10 dias.

Logo após o beneficiamento foi realizada a determinação do conteúdo de água das sementes. Foram usadas quatro repetições de quatro sementes as quais foram secas em estufa a $105^{\circ} \mathrm{C} \pm 2{ }^{\circ} \mathrm{C}$ por 17 horas (Brasil, 2009).

$\mathrm{O}$ efeito do substrato $\mathrm{e}$ da temperatura sobre $\mathrm{o}$ desempenho germinativo das sementes foi avaliado pelo teste de germinação, com quatro repetições de 16 sementes.

Os substratos testados foram sobre areia (em caixas tipo gerbox) e rolo de papel toalha. Foram testadas quatro temperaturas contínuas $\left(20,25,30\right.$ e $\left.35^{\circ} \mathrm{C}\right)$ e duas alternadas $\left(20-30\right.$ e $\left.25-35{ }^{\circ} \mathrm{C}\right)$. Os testes de germinação foram conduzidos em germinadores tipo B.O.D. com luz constante. Para reduzir a infestação por fungos nas sementes foi feita a imersão das sementes em solução de hipoclorito de sódio $2 \%$ por 10 minutos, sendo realizada logo em seguida a lavagem em água corrente por 1 minuto antes de colocá-las para germinar.

A contagem da germinação foi realizada diariamente, iniciando aos dois dias após a semeadura, sendo finalizada aos 30 dias. Considerou-se germinadas todas as sementes com protrusão do botão germinativo e crescimento da raiz primária (maior que $2 \mathrm{~mm}$ ). Foram avaliadas a porcentagem final de germinação e a velocidade de germinação por meio do T50 (tempo necessário para a germinação de $50 \%$ das sementes).

A classificação fisiológica das sementes quanto à secagem e ao armazenamento foi realizada logo após o beneficiamento. As sementes foram colocadas em sala de secagem $\left(20{ }^{\circ} \mathrm{C}\right.$ e $50 \%$ Umidade Relativa) dentro de bandeja de polietileno em camada única e foram revolvidas periodicamente para facilitar a secagem.

Para determinação da curva de secagem das sementes foi realizada a estimativa do conteúdo de água das sementes durante a secagem. Para realizar essa estimativa a massa de sementes (após determinação do conteúdo de água) foi pesada a cada 1hora nas primeiras oito horas e a partir deste ponto a cada 12 horas até o sétimo dia. A partir do sétimo dia as pesagens passaram a ser diárias até que as sementes atingissem a umidade de equilíbrio, ou seja, quando não houve mais variação de massa. Para estimativa do conteúdo de água das sementes foi utilizada a expressão proposta por DFSCI/IPGRI (1999) para a estimativa do conteúdo de água pela diferença de massa:

$$
M=\frac{(100-C A i)}{(100-C A d)} \times M i
$$

M: massa (g) no conteúdo de água desejado;

Mi: massa (g) no conteúdo de água inicial;

CAi: conteúdo de água inicial (\% base úmida);

CAd: conteúdo de água desejado ( $\%$ base úmida).

A classificação fisiológica das sementes, quanto ao comportamento durante a secagem e o armazenamento foi feita de acordo com o protocolo proposto por Hong e Ellis (1996) revisto por (Sacandé et al., 2004). Durante a secagem foram retiradas amostras de sementes com os seguintes conteúdos de água: 0,$67 ; 0,51 ; 0,36 ; 0,25 ; 0,15$ e $0,10 \mathrm{~g} \mathrm{H}_{2} \mathrm{O} \mathrm{g}^{-1}$ para a avaliação da viabilidade pelo teste de germinação. Sementes secas a 0,15 e $0,10 \mathrm{~g} \mathrm{H}_{2} \mathrm{O} \mathrm{g}^{-1}$ foram armazenadas a $-20{ }^{\circ} \mathrm{C}$ em embalagem hermética para avaliação da viabilidade aos 30, 60 e 90 dias. Os testes de germinação foram realizados em B.O.D, sob luz constante, a $30{ }^{\circ} \mathrm{C}$ em caixas tipo gerbox sobre areia.

$\mathrm{O}$ experimento foi conduzido em delineamento inteiramente ao acaso, com os tratamentos distribuídos 
em esquema fatorial $2 \times 6$ (substratos e temperaturas), em quatro repetições de 16 sementes.

Os dados obtidos foram submetidos à análise de variância e comparação de médias pelo teste de Scott-Knott a $5 \%$ de probabilidade.

\section{Resultados e Discussão}

As sementes sem secagem, embebidas sobre areia na temperatura de $30{ }^{\circ} \mathrm{C}$ iniciaram a germinação (emissão do botão germinativo) aos cinco dias, estendendo-se por no máximo 30 dias, quando a maioria das sementes germinou (iniciou o desenvolvimento da raiz primária). Em estudo sobre morfologia e caracterização da germinação de sementes de bacaba Queiroz e Bianco (2009) observaram que a germinação iniciou-se aos sete dias e se estendeu por 35 dias em condições de viveiro.

No estudo da tolerância à dessecação das sementes de $O$. bacaba, a germinação das sementes foi reduzida de $91,1 \%$ para $84,8 \%$ quando as sementes foram secas de 0,67 para $0,51 \mathrm{~g} \mathrm{H}_{2} \mathrm{O} \mathrm{g}^{-1}$ de peso seco (39,9 para 33,9\% de conteúdo de água em base úmida). As sementes não sobreviveram a secagem para $0,36 \mathrm{~g} \mathrm{H}_{2} \mathrm{O} \mathrm{g}^{-1}$ de peso seco $(26,6 \%$ de conteúdo de água em base úmida), ficando acima dos limites estabelecidos para as sementes ortodoxas e dentro dos limites encontrados para espécies recalcitrantes, propostos por Roberts (1973), Ellis et al. (1990), Hong et al. (1996) e Sacandé et al. (2004) (Figura 1). A secagem de 0,67 para 0,51 $\mathrm{g} \mathrm{H}_{2} \mathrm{O} \mathrm{g}^{-1}$ de peso seco foi realizada num período de 2 dias, enquanto o período necessário para a secagem de 0,51 para $0,36 \mathrm{~g} \mathrm{H}_{2} \mathrm{O} \mathrm{g}^{-1}$ peso seco foi de 12 dias. Sementes após secagem a 0,$25 ; 0,15$ e $0,10 \mathrm{~g} \mathrm{H}_{2} \mathrm{O} \mathrm{g} \mathrm{g}^{-1}$ e sementes secas e armazenadas a $-20{ }^{\circ} \mathrm{C}$ (com conteúdo de água de 0,15 e $0,10 \mathrm{~g} \mathrm{H}_{2} \mathrm{O} \mathrm{g}^{-1}$ ) não foram colocadas para germinar, uma vez que as mesmas já haviam perdido a viabilidade devido à secagem no conteúdo de água de $0,36 \mathrm{~g} \mathrm{H}_{2} \mathrm{O} \mathrm{g}^{-1}$, caracterizando o comportamento recalcitrante para a espécie estudada.

A família Arecaceae apresenta espécies com sementes classificadas nos três grupos propostos por (Roberts, 1973; Ellis et al., 1990). Em geral espécies associadas a ambientes mais úmidos, com ocorrência em áreas de mata ciliar como Euterpe edulis, Elaeis oleifera, Mauritia flexuosa e Bactris gasipaes apresentam sementes com sensibilidade à dessecação (Tweddle et al., 2002; Tweddle et al., 2003). Essa característica é compartilhada pela espécie em estudo, a qual, segundo Lorenzi (1996), é típica de áreas alagáveis da floresta ombrófila densa na região amazônica.

Ao final de 30 dias, quando foram encerradas as contagens de germinação, não foram observadas diferenças significativas na germinação em temperaturas constantes $\left(20,25\right.$ e $\left.30{ }^{\circ} \mathrm{C}\right)$ e alternadas $\left(20-30\right.$ e $\left.25-35^{\circ} \mathrm{C}\right)$, entretanto, sementes incubadas a $35^{\circ} \mathrm{C}$ não germinaram (Figura 2).

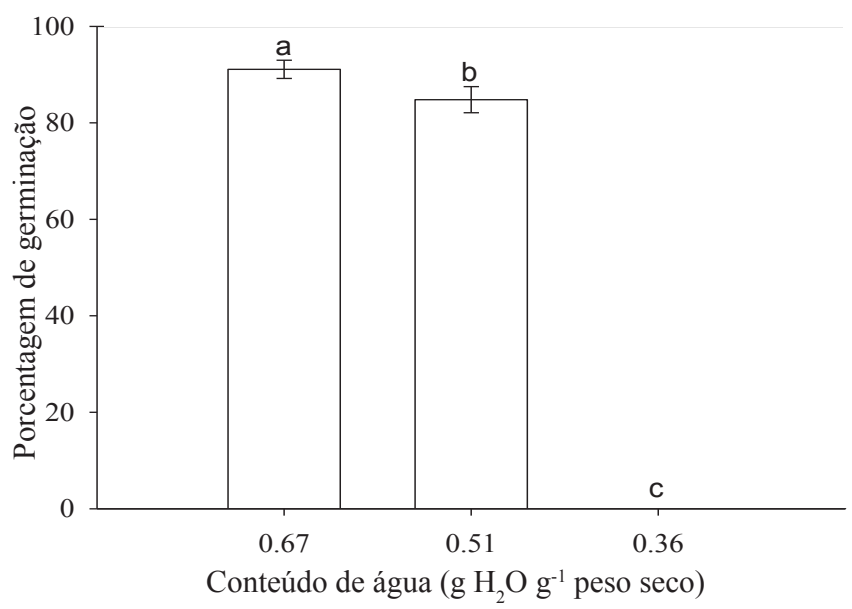

Figura 1. Efeito da secagem na germinação de sementes de Oenocarpus bacaba. Barras verticais indicam o desvio padrão. Letras diferentes indicam diferença significativa pelo teste Scott-Knott a $5 \%$ de probabilidade.

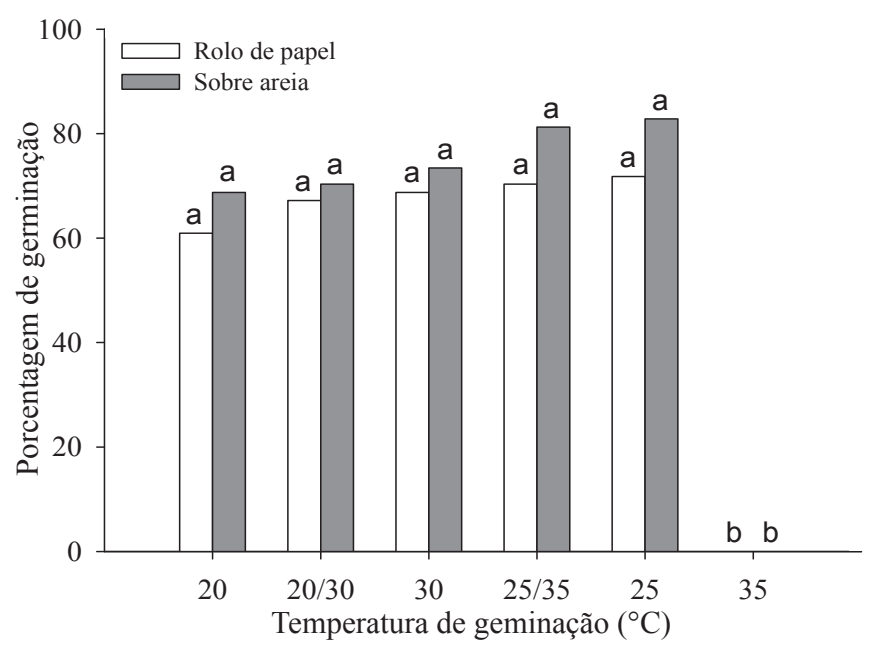

Figura 2. Germinação de sementes de Oenocarpus bacaba em temperaturas constantes $\left(20,25,30\right.$ e $\left.35^{\circ} \mathrm{C}\right) \mathrm{e}$ alternadas $\left(20 / 30\right.$ e $\left.25 / 35^{\circ} \mathrm{C}\right)$, em dois substratos (sobre areia e em rolo de papel). Letras iguais indicam que não houve diferença significativa entre os tratamentos pelo teste Scott-Knott a 5\% de probabilidade.

Em todas as outras temperaturas testadas o crescimento do botão germinativo através do endocarpo pode ser 
relacionado com a formação de plântulas 30 dias após a embebição das sementes (Figura 3), entretanto, a $35^{\circ} \mathrm{C}$ as sementes apesar de iniciarem o crescimento do botão germinativo não desenvolveram o sistema radicular, nem emitiram os primórdios foliares, ocorrendo a morte de todas as sementes dentro do período de estudo.

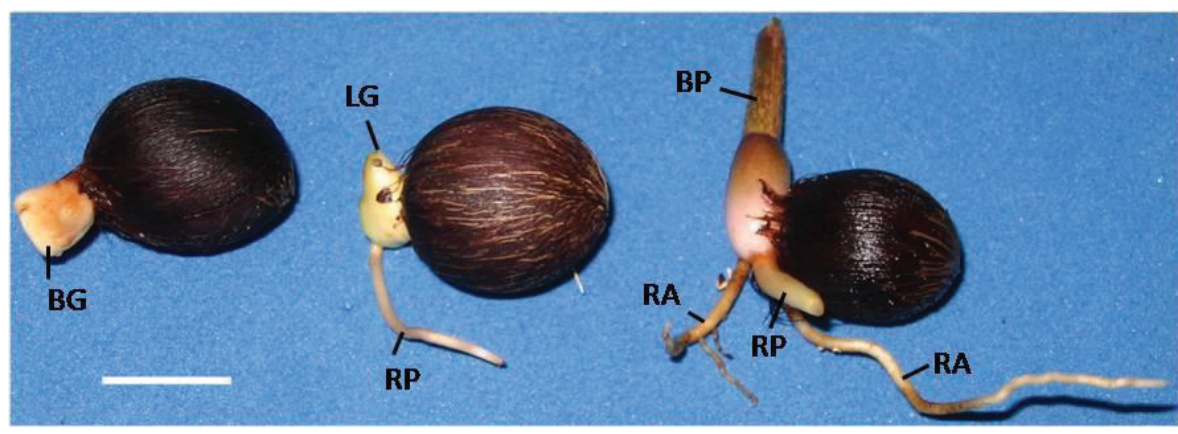

Figura 3. Germinação de sementes de Oenocarpus bacaba aos 7 dias (desenvolvimento do botão germinativo-BG), 15 dias (emissão da raiz primária-RP e formação da lígula-LG) e 30 dias (emissão de raízes adventíceas-RA e emissão da bainha protetora-BP) após a embebição a $30^{\circ} \mathrm{C}$. Barra horizontal $=1 \mathrm{~cm}$.

Ao comparar os substratos rolo de papel e sobre areia não foram verificadas diferenças significativas nas diferentes temperaturas utilizadas na germinação (Figura 2), entretanto, o desenvolvimento das plântulas foi favorecido quando a germinação foi realizada no substrato sobre areia (dados não apresentados).

Estudando a germinação de sementes da palmeira Dypsis decaryi em diferentes temperaturas e substratos, Pimenta et al. (2008) verificaram que as melhores temperaturas para a germinação foi à temperatura ambiente (variação de 24,5 à $27,5^{\circ} \mathrm{C}$ ), não havendo diferença entre os substratos testados. Sento (1972) estudando a germinação de Phoenix dactilifera também verificou que $90 \%$ das sementes germinaram em temperaturas entre $25^{\circ} \mathrm{C} \mathrm{e} 35^{\circ} \mathrm{C}$ e que os substratos utilizados (areia/vermiculita e areia/terra) foram igualmente eficientes.

Analisando o efeito da temperatura e substratos na germinação de espécies de outras famílias, Albuquerque et al. (1998) conduziram estudos com sementes de Colubrina glandulosa e recomendaram as temperaturas de 25,30 e $20-30{ }^{\circ} \mathrm{C}$ e os substratos sobre e entre vermiculita, areia e papel de filtro para o teste de germinação. Medeiros e Zanon (1998), recomendaram a utilização do substrato papel de filtro e a temperatura de $30^{\circ} \mathrm{C}$ para a germinação de sementes de Sebastiania commersoniana e papel de filtro e areia, na temperatura de $25{ }^{\circ} \mathrm{C}$ para Podocarpus lambertii. Fowler e Carpanezzi (1998) recomendaram para o teste de germinação de sementes de Mimosa bimucronata os substratos papel toalha, papel mata-borrão, areia ou vermiculita, na temperatura de $25^{\circ} \mathrm{C}$.

Apesar de não haver efeito da temperatura na porcentagem final de germinação de $O$. bacaba, verificouse efeito significativo sobre a velocidade de germinação nas sementes germinadas tanto em rolo de papel, quanto sobre areia (Figura 4). Em ambos os substratos utilizados a maior velocidade de germinação foi nas temperaturas $30^{\circ} \mathrm{C}$ constante e na temperatura alternada $25-35^{\circ} \mathrm{C}$.

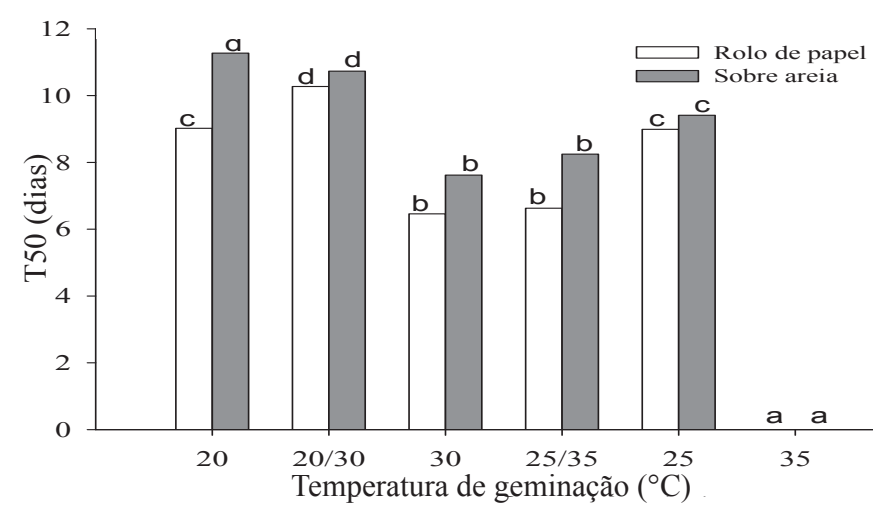

Figura 4. Velocidade de germinação (T50) de sementes de Oenocarpus bacaba em temperaturas constantes $\left(20,25,30\right.$ e $\left.35^{\circ} \mathrm{C}\right)$ e alternadas $\left(20 / 30\right.$ e $\left.25 / 35^{\circ} \mathrm{C}\right)$, em dois substratos (sobre areia e em rolo de papel). Letras diferentes indicam diferença significativa entre os tratamentos pelo teste Scott-Knott a 5\% de probabilidade.

Neste contexto, em estudo do efeito de diferentes temperaturas na germinação de sementes de quatro espécies de palmeiras: Acoelorraphe wrightii, Coccothrinax argentata, Sabal etonia e Thrinax morrisii Carpenter (1988) verificou 
que quando a germinação é realizada em temperaturas que excedem 5 a $10{ }^{\circ} \mathrm{C}$ acima ou abaixo temperatura ótima de germinação, há uma resposta negativa, resultando na redução da porcentagem final e na velocidade de germinação das sementes dessas espécies.

Por outro lado, ao contrário do encontrado por Lorenzi (1996), a germinação de sementes de bacaba, em comparação com outras espécies florestais, é relativamente rápida e uniforme. Como exemplo, Koebernik (1971), analisando a germinação de 200 espécies de palmeiras verificou que em $54 \%$ das espécies a germinação ocorreu após os 100 dias e 19\% necessitaram de mais de 200 dias para germinarem. Entretanto, a germinação de sementes de bacaba iniciou-se aos 5 dias após a embebição e apresentou um T50 que variou entre as condições testadas de 6,6 a 11,27 dias (Figura 4).

\section{Conclusões}

Sementes de $O$. bacaba são recalcitrantes e não toleram a secagem até $0,36 \mathrm{~g} \mathrm{H}_{2} \mathrm{O} \mathrm{g}^{-1}$ de peso seco;

Não há efeito das temperaturas $(20,25,30,20-30$ e 25$35^{\circ} \mathrm{C}$ ) na porcentagem final de germinação das sementes de O. bacaba;

Sementes de $O$. bacaba iniciam o desenvolvimento do botão germinativo, entretanto morrem antes de completar a germinação quando são incubadas a $35^{\circ} \mathrm{C}$;

As temperaturas que proporcionaram maior velocidade de germinação das sementes de $O$. bacaba, nos dois substratos testados, são $30^{\circ} \mathrm{C}$ (constante) e $25-35^{\circ} \mathrm{C}$ (alternadas).

O melhor substrato para germinação das sementes de $O$. bacaba é sobre areia.

\section{Referências}

ALBUQUERQUE, M.C.F.; RODRIGUES, T.J.D.; MINOHARA, L.; TEBALDI, N.D.; SILVA, L.M.M. Influência da temperatura e do substrato na germinação de sementes de saguaragi (Colubrina glandulosa Perk)Rhamanaceae. Revista Brasileira de Sementes, v.20, n.2, p.346-349, 1998.

BRASIL. Ministério da Agricultura, Pecuária e Abastecimento. Regras para análise de sementes. Ministério da Agricultura, Pecuária e Abastecimento. Secretaria de Defesa Agropecuária. Brasília: MAPA/ACS, 2009. 399p. http://www.agricultura.gov.br/arq_editor/file/laborat\%c3\%b3rio/ sementes/regras $\% 20$ para $\% 20$ analise $\% 20 \mathrm{de} \% 20$ sementes.pdf

CARPENTER, W.J. Temperature affects seed germination of four Florida palm species. HortiScience, v.23, p.336-337, 1988.

COSTA, C.J.; MARCHI, E.C. Germinação de sementes de palmeiras com potencial para produção de agroenergia. Informativo ABRATES, v.18, n.1, p.39-50, 2008.

DANIDA FOREST SEED CENTRE. Desiccation and storage protocol. Humlebaek: DFSC, 1999. p.23-40 (Technical Note, 5).

ELLIS, R.H.; HONG, T.D.; ROBERTS, E.H. An intermediate category of seed storage behaviour? I. Coffee. Journal of Experimental Botany, v.41, n.230, p.1167-1174, 1990. http://jxb.oxfordjournals.org/ content/41/9/1167.short

FOWLER, J.A.P.; CARPANEZZI, A.A. Tecnologia de sementes de marica (Mimosa bimucronata (DC) O. Ktze.). Boletim de Pesquisa Florestal, n.36, p.47-56, 1998. http://www.cnpf.embrapa.br/publica/ boletim/boletarqv/boletim36/fowler2.pdf

GOSLING, P.G. Viability testing. In: SMITH, R.D.; DICKIE, J.B.; LININGTON, S.H.; PRITCHARD, H.W.; PROBERT, R.J. (Ed.). Seed conservation: turning science into practice. London: The Royal Botanic Gardens, 2002. p.445-481.

HONG, T.D.; LININGTON, S.; ELLIS, R.H. Seed storage behaviour: a compendium. Rome: International Pant Genetic Resources Institute, 1996. (IPGRI Handbooks for Genebanks, n. 4.)

JANICK, J.; PAULL, R.E. The Encyclopedia of fruit \& nuts. Cambridge: Cambridge University, 2006. 160p.

KAHN, F.; CASTRO, A. The palm community in a forest of Central Amazonia, Brazil. Biotropica. v.17, n.3, p. 210-216, 1985. http://www. jstor.org/pss/2388221

KOEBERNIK, J. Germination of palm seed. Principes, v.15, p.134-137, 1971.

LABOURIAU, L.G. A germinação de sementes. Washington: OEA, 1983. $174 \mathrm{p}$.

LIMA, C.M.R.; BORGHETTI, F.; SOUSA, M.V. Temperature and germination of the Leguminosae Enterolobium contortisiliquum. Revista Brasileira de Fisiologia Vegetal, v.9, n.2, p.97-102, 1997. http://www. cnpdia.embrapa.br/rbfv/pdfs/v9n2p97.pdf

LORENZI, H. Palmeiras no Brasil: nativas e exóticas. Nova Odessa: Plantarun, 1996. 303p.

MARCOS FILHO, J. Fisiologia de sementes de plantas cultivadas. Piracicaba: FEALQ, 2005, 495p.

MEDEIROS, A.C.; ZANON, A. Efeito do substrato e temperatura na germinação de sementes de branquilho (Sebastiania commersoniana). Boletim de Pesquisa Florestal, n.36, p.21-28, 1998. http://www.cnpf. embrapa.br/publica/boletim/boletarqv/boletim36/medeiros1.pdf

MENDONÇA, M.S.; ARAÚJO, M.G.P. A semente de Bacaba (Oenocarpus bacaba Mart. Arecaceae): Aspectos morfológicos. Revista Brasileira de Sementes, v.21, n. p.122-124, 1999. http://www.abrates. org.br/revista/artigos/1999/v21n1/artigo18.pdf 
PIMENTA, R.S.; PIZETTA, P.U.C.; CASTRO, A.; PIVETTA, K.F.L. Germinação de sementes de Dypsis decaryi (Jum.) Beentje \& J. Dransf. (Arecaceae). Ciência e Agrotecnologia, v.32, n.5, p.1461-1466, 2008. http://www.scielo.br/pdf/cagro/v32n5/16.pdf

QUEIROZ, M.S.M.; BIANCO, R. Morfologia e desenvolvimento germinativo de Oenocarpus bacaba Mart. (Arecaceae) da Amazônia Ocidental. Revista Árvore, v.33, n.6, p. 1037-1042, 2009. http://dx.doi. org/10.1590/s0100-67622009000600006.

ROBERTS, E.H. Predicting the storage life of seeds. Seed Science and Technology, v.1, p.499-514, 1973.

SACANDÉ, M.; JOKER, D.; DULLOO, M.E.; THOMSEN, K.A. Comparative storage biology of tropical tree seeds. Rome: IPGRI, 2004. 363p.

SALOMÃO, A.N.; EIRA, M.T.S.; CUNHA, R. The effect of temperature on seed germination of four Dalbergia nigra Fr. Allem - Leguminosae. Revista Árvore, v.9, n.4, p.588-594, 1995.

SENTO, T. Studies on the seed germination of palm. V. On Chrysalidocarpus lutescens, Mascarena verschaffeltii and Phoenix dactylifera. Journal of the Japanese Society for Horticultural Science, v.41, p.76-82, 1972.
TWEDDLE, J.C.; DICKIE, J.B.; BASKIN, C.C; BASKIN, J.M. Ecological Aspects of Seed Desiccation Sensitivity. Journal of Ecology, v.91, p.294-304, 2003. http://www.jstor.org/discover/10.2307/3599764? uid $=3737664$ \&uid $=2 \&$ uid $=4 \&$ sid $=47699099271227$

TWEDDLE, J.C.; TURNER, R.M.; DICKIE, J.B. Seed Information Database, Release 3.0, 2002.

VALOIS, A.C.C. Recursos genéticos de palmeiras. http://www.procitropicos. org.br/userfiles/file/recursos $\% 20$ gen $\%$ c3\%89ticos $\% 20 \mathrm{de} \% 20$ palmeiras. doc. Acesso em: 01.mar.2011.

VIÉGAS, I.J.M.; MÜLLER, A.A. A cultura do dendezeiro na Amazônia Brasileira. Brasília: EMBRAPA. 2000, 292p.

ZEVEN, A.C. On the origin of the oil palm. Grana Palynologica, v.5, p.121-123, 1964. 